\title{
Perception of Faculty Members of Regional Medical School Toward Faculty Development Program
}

\section{Karimeldin Mohamed Ali Salihh,2,3 Abdullah M. AL-Shahrani ${ }^{4}$, Ibrahim Awad Eljac ${ }^{5}$, and Mohammed Abbas ${ }^{1,6}$}

\author{
${ }^{1}$ Pediatric Department, College of Medicine, University of Bisha, KSA \\ ${ }^{2}$ Medical Education Department, College of Medicine, University of Bisha, KSA \\ ${ }^{3}$ Pediatric Department, College of Medicine, University of Bahri, Sudan \\ ${ }^{4}$ Family Medicine, College of Medicine, University of Bisha, KSA \\ ${ }^{5}$ Community Medicine department, College of Medicine, University of Bisha, KSA \\ ${ }^{6}$ Pediatric Department, Faculty of Medicine, Kassala University, Sudan
}

Corresponding Author:

Karimeldin Mohamed Ali Salih

Received 21 February 2019

Accepted 12 May 2019

Published 30 September 2019

Production and Hosting by

Knowledge E

(c) Karimeldin Mohamed Ali

Salih et al. This article is

distributed under the terms of

the Creative Commons

Attribution License, which

permits unrestricted use and redistribution provided that the original author and source are credited.

Editor-in-Chief:

Prof. Mohammad A. M. Ibnouf

\section{Abstract}

Introduction: Any types or process of activities that are performed by a group or an individual to enhance, promote, and improve the performance, competencies or skills of a health professional at an institute level are defined as faculty development which has many other names like staff development, academic development, and educational development. The importance of faculty development stressed by Harden is equivalent to curriculum development, which is a very difficult assignment.

Objectives: To determine the pattern of faculty members' perception toward their weekly faculty development program.

Methodology: Enrolling the faculty members of the College of Medicine, University of Bisha, Kingdom of Saudi Arabia (COM/UB,KSA). COM/UB adopting the innovative curriculum (problem-based learning, team-based learning, interactive lectures, and case-based learning and seminars. Each Tuesday, faculty members gather in the faculty development academic program (FDAP) room to discuss issues related to medical education and quality. Usually, there is a presentation on the selected topic over $25 \mathrm{~min}$, followed by a discussion and workshop, and finally, a recommendation is drawn. The inclusion criterion is those staying in the college for a period of more than one year. New joiners and those staying for a period of less than one year were excluded. Faculty members were enrolled optionally and requested to fill a validated questionnaire.

Results: The response rate was $92 \%$ of total staff. More than $89 \%, 87 \%, 86 \%$ and $74 \%$ thought that the FDAP is useful to them, helps them in addressing academic issues in the faculty, is an enriching experience, and thought that it helps them in constructing high-quality multiple choice questions (MCQs). Finally, 84\% were interested in presenting topics in FDP.

Conclusion: FDAP was positively perceived by the faculty members of the University Bisha/College of Medicine, since it enriches their experience and satisfies their academic job. 


\section{Introduction}

Any types or process of activities that are performed by a group or an individual to enhance, promote, improve the performance, competencies, or skills of the health professional at the institutional level is defined as faculty development, which has many other synonymous names such as staff development, academic development, educational development $[1,2]$. Faculty development refers to a range of activities that are perceived to help academicians in improving their professional skills that are vital for carrying out their teaching, research, or administrative activities in medical education [3]. In medical education conventions, faculty development has been considered to play a decisive role in sustaining academic vitality [4]. Faculty development program (FDAP) has been considered as a stand-alone educational pedagogy in fostering knowledge and professional skills of faculty [5]. However, few studies have provided objective reports about the impact of such programs in a healthcare system. Many education specialists consider faculty development as the process of improving instructor's skills and conducting any other rules that can promote the entire institution [2-4]. The strategies for improving the learning environment include: effective use of available resources with the emphasis on integrating technology in teaching, providing easy and comfortable access to various information communication technology tools, and establishing learning centers equipped with all required technology. Similar to these strategies, Guze [6] emphasized the importance of using technology as an infrastructure to enhance learning environment and as a basis to address many of the challenges facing medical education. Most specialists consider faculty development as an essential component of medical education that helps teachers to act precisely, accurately, and confidently from undergraduate to continuing learning [7-9]. The explosion of medical technology, patient care, medical education reform, and innovations became a continuous process without end. Since the World Federation of Medical Education (WFME) suggested that the integration of courses should continue from undergradutes up to the phase of continuous education, the need for a sort of program has been created to update medical staff in general and faculty in particular [10]. In order for the faculty members to provide skillful instruction, valid assessment, fulfilling the mission of the institute, and to be accountable, a continuous education on competencies that are missed during their own training can be enhanced by the faculty development activities in their institute on a regular basis [11]. In order to integrate community needs for medical schools, health professionals in general and faculty members in particular should adhere to innovative instruction and assessment within an innovative curriculum $[12,13]$. This era 
of quality makes many international bodies like the WFME, the Association for Medical Education in Europe (AMEE) and others in North America and Canada to persuade educational quality, and hence the development and continuous training of faculty members cannot be over-emphasized [14]. If the institute is fighting for accountability, accreditation, and implementation of the mission to achieve success, productivity, and satisfaction, much resources and time should be directed toward faculty development (15). The importance of faculty development was stressed by Harden (2009) as being equivalent to curriculum development, which is a very difficult assignment [16, 17]. The question that needs an urgent answer is how do the faculty members of the College of Medicine, University of Bishah (COM/UB) perceived their faculty development program that is conducted weekly [18-20]. The curriculum of COM/BU is an innovative one, which needs continuous faculty development academic program (FDAP) to familiarize the instructor with its science, as most of them have not practiced it before [21]. The objective of this study is to determine the pattern of faculty members' perception toward a faculty development program.

\section{Methods}

This study was conducted in the College of Medicine/University of Bishah (KSA), which was founded four years ago. The learning process included problem-based learning $(\mathrm{PBL})$, team-based learning (TBL), seminars, and case-based learning (CBL) either in skill labs, hospital, or classroom. Assessment was done through multiple choice questions (MCQs), structured short answers (SSA), objective structured practical exam (OSPE), and objective structured clinical exam (OSCE).

\subsection{Setting up the FDAP}

The FDAP is conducted every Tuesday between 10 am and $12 \mathrm{pm}$ to improve the staff's teaching skills. The topics in medical education, quality and researches are selected, and then a staff who is senior or well-trained in any one of the selected topic delivers a presentation for $25 \mathrm{~min}$, this is followed by a workshop and a discussion, and finally some recommendation is made for the work quality improvement based on the international guidelines for medical education and quality $[22,23]$. 


\subsection{Data collection and analysis}

A well-structured validated questionnaire which reflect the real needs from the faculty in order to conduct their work and execute their curriculum effectively has been designed by an expert in medical education and quality assurance. Although the total population of our staff is small, the enrolment was optional. The population targeted for the research was the entire staff in the college who are about 40 faculty members, of which 37 answered the question with a response rate of $92 \%$. The inclusion criterion included the staff working in the college for at least more than one academic year and the exclusion criterion was those who had just joined the college recently (less than one year) as they were yet not in a position to perceive the faculty development program (i.e., less exposure). The questionnaires distributed to the included staff manually as hard copy requested them to fill it personally, voluntarily, individually, and anonymously. The filled questionnaire was received by the author for analysis. An acceptance to be enrolled was considered as consent [24, 25].

\subsubsection{Statistical analysis}

SPSS version 21, descriptive statistics was used, $p$-value was used with 0.05 confidence level to reject the null hypothesis for analysis, and the permission was taken from the COM research committee. An agreement of the staff to be enrolled was considered as informed consent.

\section{Results}

\subsection{Teaching background of the faculty members}

The response rate was $92 \%$, and $71.875 \%, 9.375 \%$, and $18.75 \%$ received their undergraduate by classical, innovative, and hybrid curriculum, respectively.

\subsection{Faculty member's teaching experience before joining the uni- versity}

Almost $56.25 \%$ of the faculty members practiced teaching through innovative curriculum before. 


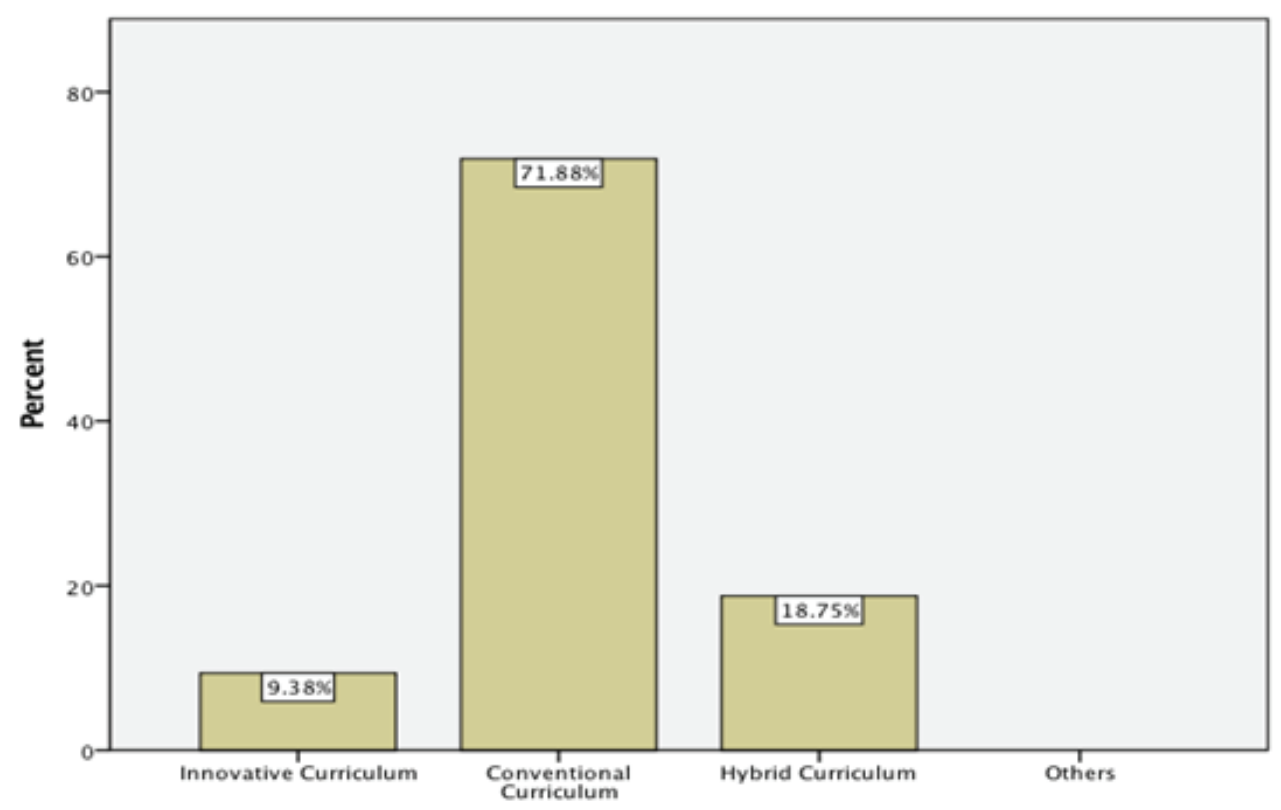

Figure 1: Mode of receiving undergraduate studies.

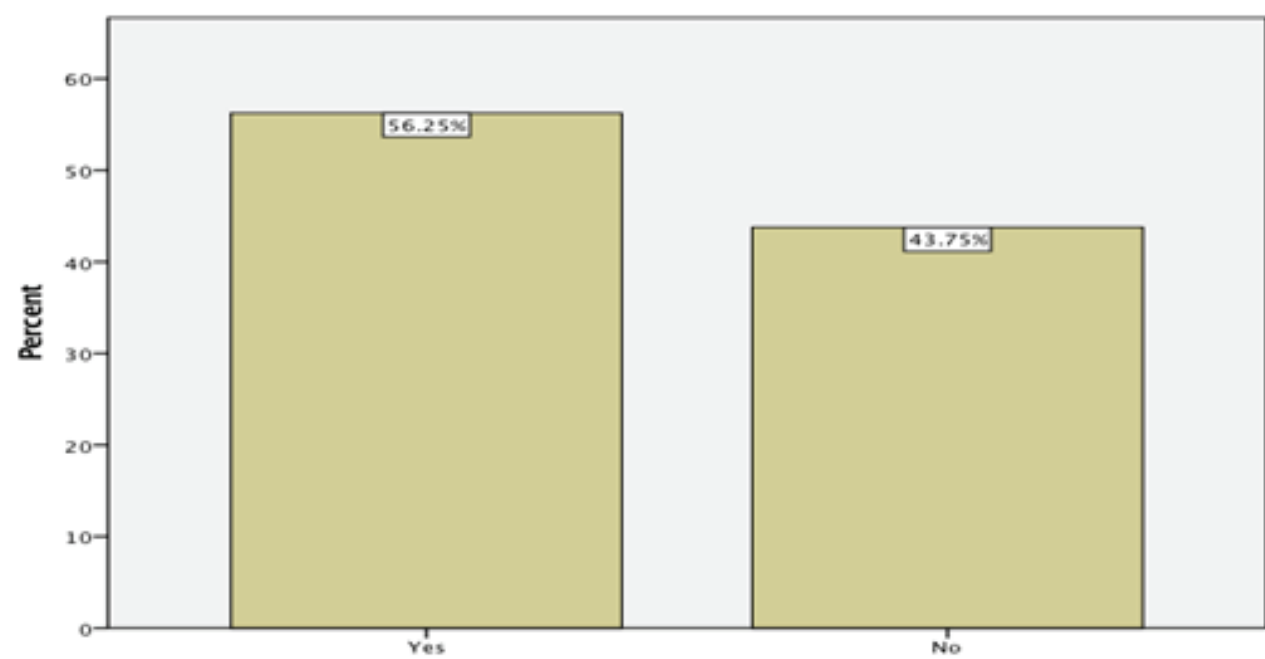

Figure 2: Staff practicing innovative methods of instruction before joining UB/COM.

\subsection{Faculty member's participation in FDAP}

Staff member participated actively $<10,10-15$, and $>15$ times in participation in FDAP by $12.5 \%, 25.0 \%$, and $62.5 \%$, respectively. 


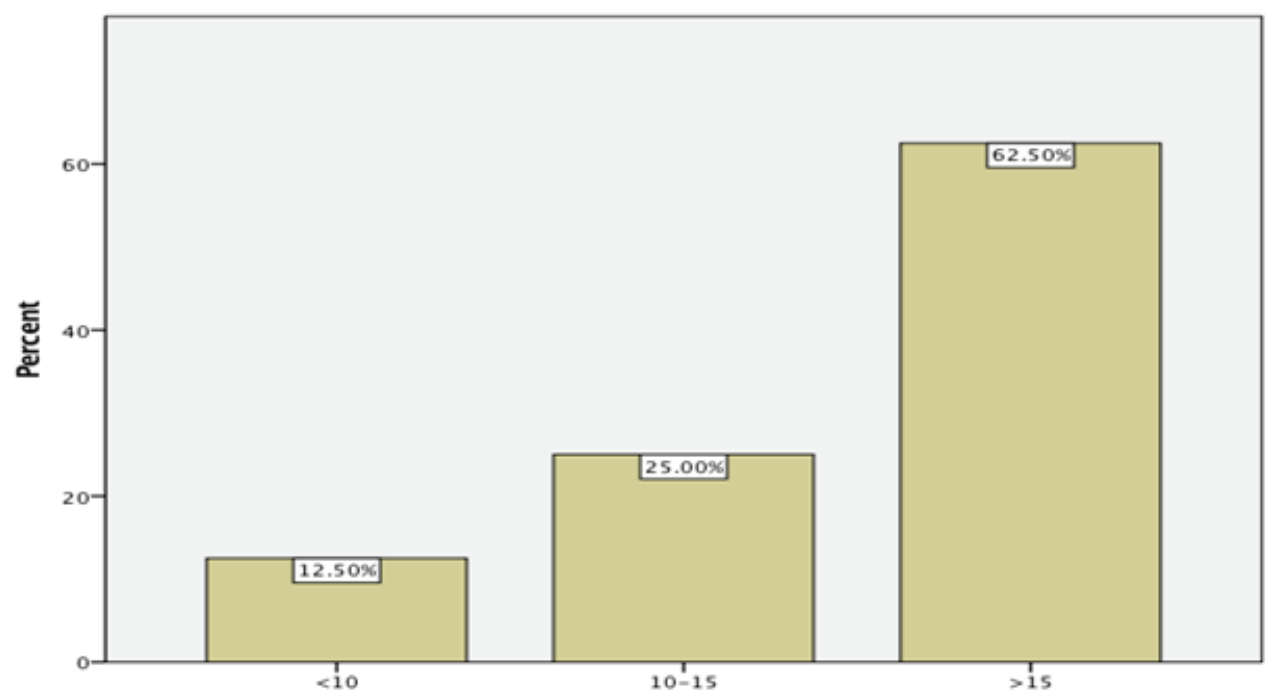

Figure 3: Staff presentations in FDM UB/COM

\subsection{Characteristic of participation in FDAP}

More than $83 \%, 9 \%$, and $6 \%$ of the staff regularly participate, rarely participate, and do not participate, respectively.

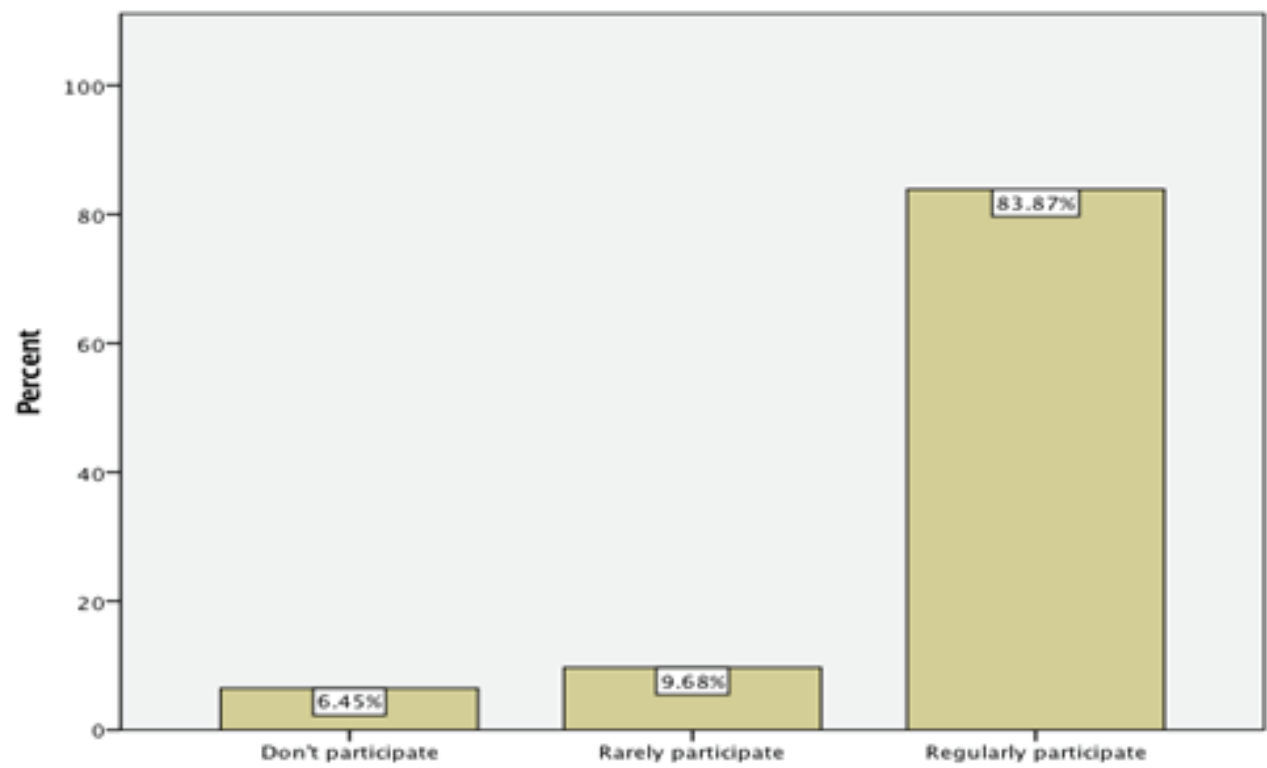

Figure 4: Characterization of staff's participation in the FPD in UB/COM.

\subsection{FDP direct/indirect outcomes}

More than $89 \%$ feel FDAP is useful to them, more than $87 \%$ mentioned that it helps them in addressing academic issues among the faculty members; $86 \%$ consider it as enriching, $84 \%$ are interested in presenting topics in FDP rather than their experiences, 
and finally, 74\% thought that FDAP helps them in constructing high-quality MCQs. With an obvious significant impact $(p<0.05)$ of the faculty member's perception toward their FDAP, the faculty staff skills in innovative curriculum was improved. Indirect outcome: develop the university ranking and accreditation.

\section{Discussion}

From this study, it is very obvious that most staff members came from the non-innovative curriculum with significant response 0.05, yet they make use of attending and participating in FDAP, which indicates its usefulness in providing chances for learning new skills, as proved by other studies [26-28]. The study observed that $84 \%$ of the faculty members are interested in the presentation, which is in agreement with other studies [29, 30], while $86 \%$ consider it as enriching their experience as teaching staff, which add a lot of skills to them, in finding that it is confirmed by other authorities (31). Despite the heavy work and follow-up on our presentation, the rate of positive perception of the staff to the topics is covers all medical domains, the outcomes as in any other studies might be explained by having innovative curriculum and perhaps the staff experience of assessing the presentations is well developed since the college started functioning FDAP three years ago. Faculty members who participated in this study also valued the need for curriculum reform with the emphasis on: learners' need to demonstrate competencies, the shift from content based- to outcomes-based curricula, making the medical education curriculum more student-centered than teachercentered and more integrated both horizontally and vertically and problem-based. The strategy measures for change implementation in medical education in Saudi Arabia, according to the results of current study, include: curriculum reform, faculty development and improving the learning environment. These strategies should be combined with organizational measures that facilitate the change process and overcome obstacles against change [32, 33]. The interest on FDAP and the positive attitude toward FDAP definitely will build a feeling of strong belonging to the institute as pointed out by some authorities [34], however, this feeling will create strong challenges for motivation to the administration $[20,21]$; $74 \%$ thought that FDP helps them in constructing highquality MCQs. Although, teachers who adopt their job might do it more accurately if they respond adequately [35]. At the beginning of the learning methods of FDAP, lecturer should explain the purpose of learning, build a positive attitude toward the subject, and describe something that is expected by the students [36]. Lecturers must first explain the processes and procedures in detail in order to better understand 
this method and [37]. The tutors must teach the students that the main objective of students to search and learn a large amount of information is to investigate critical issues related to the case. During the phase of the investigative lesson, the students are encouraged to critically evaluate the articles being investigated [38]. Hamza et al. (2015) who wrote a scientific report in KSA found that FDAP really improves MCQs writing, which supports our findings, since it is within the same context [39], together with other findings in USA items writing for USMLE [40]. Positive perceptions found include: being an active learner; being a systematic learner; developing friendly relationships; adjusting personal characteristics when learning; and having freedom while learning. These are consistent with the findings from this study. It is warranted to measure these perceived benefits with reliable and valid tools over time in future research [41]. Area for improvement: this results reflect small size population, absence of randomization. All positive perception of the staffs need validation and evaluation through the verification of students' performance, behavior, and professionalism that should be carried out when evaluating the usefulness of FADP [42]. The professional development and academic stature of an institution's faculty members are connected to its educational vivacity [43]. This can be materialized by a dynamic and energetic FDP that has been shown to lead to the enhancement of faculty's skills in all the five desired domains, that is, teaching, assessment, curriculum support, organizational leadership, and mentoring [43]. Faculty development endorses the educational improvements and strategies that are dignitary and are executed in a professional manner. Professional organizations and experts have recommended FDPs for greater awareness and attainment of knowledge in teaching and learning [44]. Strength: this current work draws the attention of policymakers in high educational institutes to the importance of changing opinions and experience between faculty members from different educational backgrounds, and moreover addresses the teamwork interaction, collaboration, and continuous medical education [45].

\section{Conclusion}

In an era of technology and information, a single person experience is not enough for coping with innovation in high education. Therefore, Faculty development adds experience to faculty members, regardless of their previous education, experience, and practice. 


\section{Recommendation}

It is highly recommended for every medical institute to develop FDAP to improve performance and to evaluate the FDAP.

\section{Conflict of Interest}

The authors declare that there is no conflict of interest.

\section{Author's' Contribution}

Karimeldin Mohamed Ali Salih is the principle investigator and contributed in final layout, discussion, and methodology; Abdullah M. AL-Shahrani helped in the layout and revision of the article and samples; Ibrahim Awad Eljac contributed in the analysis of data; and Mohammed Abbas contributed in the introduction, discussion.

\section{References}

[1] Cui, G., Yuan, A., Zhu, L., et al. (2017). Increased expression of interleukin-21 along colorectal adenoma-carcinoma sequence and its predicating significance in patients with sporadic colorectal cancer. Clinical Immunology, vol. 183, pp. 266-272.

[2] Toth, B., Weynants, M., Nemes, A., et al. (2015). New generation of hydraulic pedotransfer functions for Europe. European Journal of Soil Science, vol. 66, no. 1, pp. 226-238.

[3] Yuen, E. Y., Knight, T., Dodson, S., et al. (2014). Development of the Health Literacy of Caregivers Scale - Cancer (HLCS-C): item generation and content validity testing. BMC Family Practice, vol. 15, p. 202.

[4] Amin, Z., Eng, K. H., Seng, C. Y., et al. (2009). A multi-institutional survey on faculty development needs, priorities and preferences in medical education in an Asian medical school. Medical Education Online, vol. 14, p. 16.

[5] Bilal, Guraya, S. Y., and Chen, S. (2019). The impact and effectiveness of faculty development program in fostering the faculty's knowledge, skills, and professional competence: a systematic review and meta-analysis. Saudi Journal of Biological Sciences, vol. 26, no. 4, pp. 688-697.

[6] Guze, P. A. (2015). Using technology to meet the challenges of medical education. Transactions of the American Clinical and Climatological Association, vol. 126, pp. 
$260-270$.

[7] Petryshyn, O. V., Shapoval, E. Y., and Novik, S. M. (2019). The physiological characteristic system control of working activity in the process of training prospective healthcare professionals. Wiadomości Lekarskie, vol. 72, pp. 1059-1063.

[8] Fehlmann, A., Abbiati, M., Dallenbach, P., et al. (2019). Motives influencing students' preferences for obstetrics and gynaecology speciality: a cross-sectional multi-site Swiss study. European Journal of Obstetrics \& Gynecology and Reproductive Biology, vol. 237, pp. 157-163.

[9] Valbuena, G., O'Brien, B., Ten Cate, O., et al. (2019). Inquiry in the medical curriculum: a pedagogical conundrum and a proposed solution. Academic Medicine, vol. 94, no. 6, pp. 804-808.

[10] Kleinpell, R., Ely, E. W., Williams, G., et al. (2011). Web-based resources for critical care education. Critical Care Medicine, vol. 39: pp. 541-553.

[11] Roze des Ordons, A. L., Doig, C. J., Couillard, P., et al. (2017). From communication skills to skillful communication: a longitudinal integrated curriculum for critical care medicine fellows. Academic Medicine, vol. 92, no. 4, pp. 501-505.

[12] Rourke, J. (2018). Social accountability: a framework for medical schools to improve the health of the populations they serve. Academic Medicine, vol. 93, no. 8, pp. $1120-1124$.

[13] Sachdeva, A. K. (2000). Faculty development and support needed to integrate the learning of prevention in the curricula of medical schools. Academic Medicine, vol. 75, no. 7, pp. S35-S42.

[14] Ahmady, S., Changiz, T., Brommels, M., et al. (2009). Contextual adaptation of the Personnel Evaluation Standards for assessing faculty evaluation systems in developing countries: the case of Iran. BMC Medical Education, vol. 9, p.18.

[15] Hawkins, R. E., Welcher, C. M., Holmboe, E. S., et al. (2015). Implementation of competency-based medical education: are we addressing the concerns and challenges? BMC Medical Education, vol. 49, no. 11, pp. 1086-1102.

[16] Gospodarevskaya, E., Carter, R., Imms, C., et al. (2019). Economic evaluation of simulated and traditional clinical placements in occupational therapy education. Australian Occupational Therapy Journal, vol. 66, no. 3, pp. 369-379.

[17] Zhou, X., Zheng, R., Liu, G., et al. (2017). Desiccation treatment and endogenous IAA levels are key factors influencing high frequency somatic embryogenesis in cunninghamia lanceolata (lamb.) hook. Frontiers in Plant Science, vol. 8, p. 2054. 
[18] Sinclair, M., Raimo, J., Wong, K., et al. (2019). A novel curriculum to prepare internal medicine residents for fellowship interviews. Journal of Medical Education and Curriculam Development, vol. 6, p. 2382120519855939.

[19] Dinius, J., Hammer, A., Manser, T., et al. (2019). Piloting and evaluating feasibility of a training program to improve patient safety for inter-professional inpatient care teams - study protocol of a cluster randomized controlled trial. Trials, vol. 20, no. 1, p. 386.

[20] Gommers, C. M. M., Buti, S., Tarkowska, D., et al. (2018). Organ-specific phytohormone synthesis in two Geranium species with antithetical responses to far-red light enrichment. Plant Direct, vol. 2, no. 8, p. e00066.

[21] Haley, J., McCall, R. C., Zomorodi, M., et al. (2019). Interprofessional collaboration between health sciences librarians and health professions faculty to implement a book club discussion for incoming students. Journal of the Medical Library Association, vol. 107, no. 3, pp. 403-410.

[22] Barry, E. S., Dong, T., Durning, S. J., et al. (2019). Medical student leader performance in an applied medical field practicum. Military Medicine.

[23] McKinney, C. M., Mookherjee, S., Fihn, S. D., et al. (2019). An Academic research coach: an innovative approach to increasing scholarly productivity in medicine. Journal of Hospital Medicine, vol. 14, pp. E1-E5.

[24] Kusumawati, H. I., Magarey, J., and Rasmussen P. (2019). Analysis of factors influencing length of stay in the Emergency Department in public hospital, Yogyakarta, Indonesia. Australasian Emergency Care.

[25] Wihardja, H., Hariyati, R. T. S., and Gayatri, D. (2019). Analysis of factors related to the mental workload of nurses during interaction through nursing care in the intensive care unit. Enfermería Clínica.

[26] Machado, S., Jansen, P., Almeida, V., et al. (2019). Is tDCS an adjunct ergogenic resource for improving muscular strength and endurance performance? A systematic review. Frontiers in Psychology, vol. 10, p. 1127.

[27] Fitzpatrick, S. A., Haswell, M. R., Williams, M. M., et al. (2019). Learning about aboriginal health and wellbeing at the postgraduate level: novel application of the growth and empowerment measure. Rural Remote Health, vol. 19, no. 2, p. 4708.

[28] Marta, W., Michal, C., and Grazyna, N. (2019). TNF-alpha G-308A genetic variants, serum CRP-hs concentration and DNA damage in obese women. Molecular Biology Reports.

[29] DuCoin, C., Petersen, R. P., Urbach, D., et al. (2018). Update regarding the society of American Gastrointestinal and Endoscopic Surgeons (SAGES) grant distribution 
and impact on recipient's academic career. Surgical Endoscopy, vol. 32, no. 7, pp. 3041-3045.

[30] DeSimone, A. K., Haydek, J. P., Sudduth, C. L., et al. (2017). Encouraging student interest in teaching through a medical student teaching competition. Academic Medicine, vol. 92, no. 8, pp. 1128-1132.

[31] McSparron, J. I., Huang, G. C., and Miloslavsky, E. M. (2018). Developing internal medicine subspecialty fellows' teaching skills: a needs assessment. BMC Medical Education, vol. 18, no. 1, p. 221.

[32] Reynolds, A. K. (2019). Academic coaching for learners in medical education: twelve tips for the learning specialist. Medical Teacher, pp. 1-6.

[33] McDaniel, C. E., Singh, A. T., Beck, J. B., et al. (2019). Current practices and perspectives on peer observation and feedback: a national survey. Academic Pediatrics.

[34] van Boekholt, T. A., Duits, A. J., and Busari, J. O. (2019). Health care transformation in a resource-limited environment: exploring the determinants of a good climate for change. Journal of Multidisciplinary Healthcare, vol. 12, pp. 173-182.

[35] McKeon, B. A., Ricciotti, H. A., Sandora, T. J., et al. (2019). A Consensus guideline to support resident-as-teacher programs and enhance the culture of teaching and learning. Journal of Graduate Medical Education, vol. 11, no. 3, pp. 313-318.

[36] Daniel, M., Rencic, J., Durning, S. J., et al. (2019). Clinical reasoning assessment methods: a scoping review and practical guidance. Academic Medicine, vol. 94, no. 6, pp. 902-912.

[37] Homberg, A., Hundertmark, J., Krause, J., et al. (2019). Promoting medical competencies through a didactic tutor qualification programme - a qualitative study based on the CanMEDS physician competency framework. BMC Medical Education, vol. 19, no. 1, p. 187.

[38] Celebi, N., Griewatz, J., Malek, N. P., et al. (2019). Development and implementation of a comprehensive ultrasound curriculum for undergraduate medical students - a feasibility study. BMC Medical Education, vol. 19, no. 1, p. 170.

[39] Hamza, A. H., Abdulfattah, H. M., Mahmoud, R. H., et al. (2015). Current concepts in pathophysiology and management of hepatocellular carcinoma. Acta Biochimica Polonica, vol. 62, no. 3, pp. 573-580.

[40] Fayed, R., Hamza, D., Abdallah, H., et al. (2017). Do we need regional guidelines for breast cancer management in the MENA region? MENA Breast Cancer Guidelines project. Ecancermedicalscience, vol. 11, p. 783. 
[41] Bowen, J. L., Ilgen, J. S., Regehr, G., et al. (2019). Reflections from the rearview mirror: internal medicine physicians' reactions to clinical feedback after transitions of responsibility. Academic Pediatrics.

[42] Odajima, Y., Kawaharada, M., and Wada, N. (2017). Development and validation of an educational program to enhance sense of coherence in patients with diabetes mellitus type 2. Nagoya Journal of Medical Science, vol. 79, no. 3, pp. 363-374.

[43] Guraya, S. Y., Norman, R. I., Khoshhal, K. I., et al. (2016). Publish or Perish mantra in the medical field: a systematic review of the reasons, consequences and remedies. Pakistan Journal of Medical Sciences, vol. 32, no. 6, pp. 1562-1567.

[44] Maguire, S., Li, A., Cunich, M., et al. (2019). Evaluating the effectiveness of an evidence-based online training program for health professionals in eating disorders. Journal of Eating Disorders, vol. 7, p. 14.

[45] AlKhaldi, M., Abed, Y., Pfeiffer, C., et al. (2018). Assessing policy-makers', academics' and experts' satisfaction with the performance of the Palestinian health research system: a qualitative study. Health Research Policy and Systems, vol. 16, no. 1, p. 66. 